\title{
Increased occurrence of ACL injuries for football players in teams changing coach and for players going to a higher division
}

\author{
Alexander Sandon $^{1}$ (D) Werner Krutsch ${ }^{2} \cdot$ Volker Alt $^{2} \cdot$ Magnus Forssblad $^{1}$
}

Received: 3 February 2021 / Accepted: 30 April 2021 / Published online: 13 May 2021

(c) The Author(s) 2021

\begin{abstract}
Purpose To identify football-specific factors associated with ACL injuries that can be targeted for sport-specific injury prevention.

Methods A study-specific questionnaire was developed to study the characteristics of ACL injuries in football including intrinsic, extrinsic, and injury specific factors. The questionnaire was available at the Swedish national knee ligament registry's website for the football players to voluntarily fill out. Data are presented on group level for all football players in total and for females and males separate to examine gender-specific differences. The results are based on answers collected over a 3-year period from 2875 football players, 1762 (61\%) males and $1113(39 \%)$ females.

Results ACL were more frequently sustained during games $66 \%$ than during practices $25 \%$. The injury mechanism was non-contact in 59\% and contact in $41 \%$. For the contact injuries during games, no action was taken by the referee in $63 \%$ of the situation and a red card was shown in $0.5 \%$. The risk of ACL injury was highest early in the football game with $47 \%$ sustained during the first $30 \mathrm{~min}$ and $24 \%$ in the first $15 \mathrm{~min}$. Players changing to a higher level of play $15 \%$ had a higher rate of ACL injuries than players changing to a lower level $8 \%$. This difference was especially seen in female football players with $20 \%$ of ACL injuries being sustained by players going to a higher division compared to $7 \%$ for those going to a lower division. $15 \%$ of the male and $21 \%$ of the female ACL injuries occurred in teams with a coach change during the season. Knee control exercises to warm up was used by $31 \%$ of the female players and $16 \%$ of the males. $40 \%$ of the players reported that they did not plan on returning to football.

Conclusion Neuromuscular training programs have proven to reduce ACL injuries, but greater adherence to these remains a challenge as only 1 in 5 of the ACL-injured football players report using them. Teams changing coach and players going to a higher division appear to have an increased risk of ACL injury warranting attention and further investigations.

Level of evidence IV.
\end{abstract}

Keywords ACL $\cdot$ ACL injury $\cdot$ Football $\cdot$ Soccer $\cdot$ Return to sports

\section{Introduction}

Football is a physically demanding sport involving highspeed runs, pivoting activities, and contact situation that might result in an injury. A recent long-time follow-up of professional football identified a wide range of football

Alexander Sandon

Alexander.sandon@ki.se

1 Department of Molecular Medicine and Surgery, Stockholm Sports Trauma Research Center, Karolinska Institute, Stockholm, Sweden

2 Department of Trauma Surgery, University Medical Center Regensburg, Regensburg, Germany related injuries. One of the most severe injuries with the longest lay off from football was an Anterior Cruciate Ligament (ACL) injury [8]. ACL injuries are often viewed in the light of how it affects the players' football career. Reconstructive surgery is often performed to restore knee stability and to allow a return to football. For professional players, the lay of from football is most cases more than 6 months, but the return rate is very high $[16,27]$. In amateurs, the return rate is considerably lower and only just over half the players return to football $[4,21]$. Another aspect is how football affects the future knee health of the player. A recent study following the most talented youth players in Sweden found that as many as $10 \%$ of the players underwent ACL reconstruction during the follow-up period [22]. In the 
Scandinavian knee ligament registries, the cause of the ACL injuries is football in about $40 \%$ of patients [11]. The risk of developing osteoarthritis is high after an ACL injury [2], and it is there for important to try to prevent and reduce the number of ACL injuries.

For the present study, a questionnaire was developed for male and female players to study the characteristics of ACL injury in football. The hypothesis was that there are footballspecific factors associated with ACL injuries and the main objective of the study is to try to identify such factors that can be targeted for sport-specific injury prevention.

\section{Materials and methods}

The research was approved by the regional ethics committee in Stockholm ID 2011/337-31/3 and Linköping ID 2020-03747.

A study-specific questionnaire was created to try to identify football-specific factors associated with ACL injuries. The questionnaire was initially developed in Germany for the national 'German ACL Registry in Football' and later adopted and translated into Swedish [14]. The Swedish version of the questionnaire was made available for ACLinjured patients on the website of the Swedish National Knee Ligament Registry (SNKLR) in 2017. The SNKLR was established in 2005 as a surgical registry for ACL injuries and has recently started to also include non-surgically treated patients [1]. The patients in the registry are asked to fill out patient reported outcome measures (PROMs) like the Knee Injury and Osteoarthritis Outcome Score (KOOS) and the EuroQol 5-D (EQ-5-D) before surgery and at 1, 2, 5 , and 10 year follow-up $[19,20]$. As the patients log on to the SNKLR to fill out these other PROMs, the present studyspecific questionnaire was available for football players to voluntarily fill out. Answers to the questionnaire have been collected for 3 years.

\section{Study-specific questionnaire}

An ambition to identify football-specific characteristics of ACL injuries resulted in the inception of the present questionnaire. The development of the questionnaire began in 2015 when an increase in ACL injuries was found after the implementation of new professional football league in Germany [17]. The suspicion was that ACL injuries in football may be influenced by many different intrinsic and extrinsic factors and that some of them might be available for intervention to reduce the number or injuries. A wide variety of different player-specific characteristics, field-specific characteristics, as well as short-term changes on players` ability and performance were analyzed in detail. All the variables in the questionnaire are presented in the Results section.

\section{Statistical analyses}

All statistical analyses were conducted in IBM SPSS version 27. All data were anonymized before the statistical analysis. Descriptive statistics were calculated for all study variables. The data are presented on group level for all football players in total and for females and males separate to examine gender-specific differences.

\section{Results}

The results are based on answers from 2875 football players, 1762 (61.3\%) males and 1113 (38.7\%) females. The mean age of the male players was 4.5 years older than for the female payers. Anthropomorphic data are available in Table 1. For both male and female players, the Body Mass Index (BMI) had a normal distribution.

For both male and female players, defenders (37.1\%) and midfielders (36.8\%) were the positions who sustained most of the ACL injuries and only 5.2\% of the ACL-injured players were goalkeepers. The players were predominantly right footed $(81.1 \%)$. Twice as many of the male football players (13.3\%) were left-footed compared to the female players (6.6\%). ACL injuries occur to football players at all levels. However, most of the ACL injuries were sustained by footballers playing at the lower levels (Table 2).

ACL injuries were more common in the right leg (53.5\%) than in the left leg $(46.5 \%)$. For both male and female players, the ACL injury most often occurred in games (65.7\%) rather than practices $(24.8 \%)$ with the remaining $(9.5 \%)$ happening in other types of situation for example playing recreational among friends. The males sustained more ACL injuries during home games and the female more during away games. The player reported injury mechanism was non-contact for $59.1 \%$ and contact for $40.9 \%$. For the contact injuries during games, no action was taken by the referee in $63.1 \%$ of the situation and a straight red was shown in only $0.5 \%$ of the situation. Although most stopped playing after sustaining the ACL injury 3.9\% managed to continue

Table 1 Anthropomorphic data of male and female anterior cruciate ligament injured male and female football players $(n=2875)$

\begin{tabular}{llllll}
\hline Variable & \multicolumn{3}{l}{ Male } & & \multicolumn{2}{l}{ Female } \\
\cline { 2 - 3 } \cline { 6 - 7 } & $n 1762$ & $61.3 \%$ & & $n 1113$ & $38.7 \%$ \\
& Mean & SD & & Mean & SD \\
\hline Age (years) & 28.4 & 7.9 & & 23.9 & 9 \\
Height (cm) & 181 & 6.5 & & 167 & 5.9 \\
Weight (kg) & 81 & 11.3 & 66 & 9 \\
Body mass index (BMI) & 24.9 & 3 & & 23.4 & 2.8 \\
\hline
\end{tabular}


Table 2 Football-specific data for ACL-injured football players $(n=2875)$

\begin{tabular}{|c|c|c|c|}
\hline Variable & $\begin{array}{l}\text { Total } \\
\%\end{array}$ & $\begin{array}{l}\text { Male } \\
\%\end{array}$ & $\begin{array}{l}\text { Female } \\
\%\end{array}$ \\
\hline \multicolumn{4}{|l|}{ Position } \\
\hline Goalkeeper & 5.2 & 4.8 & 5.8 \\
\hline Defender & 37.1 & 36.5 & 38 \\
\hline Midfielder & 36.8 & 37.5 & 35.6 \\
\hline Forward & 21 & 21.2 & 20.6 \\
\hline \multicolumn{4}{|l|}{ Dominant leg } \\
\hline Right & 81.1 & 79.2 & 84.1 \\
\hline Left & 10.7 & 13.3 & 6.6 \\
\hline Two-footed & 8.2 & 7.5 & 9.3 \\
\hline \multicolumn{4}{|l|}{ Level of play } \\
\hline Swedish top division & 2.8 & 2.1 & 4 \\
\hline Division 2 & 1.6 & 0.9 & 2.6 \\
\hline Division 3 & 6.6 & 2.1 & 13.7 \\
\hline Division 4 & 11.5 & 5.1 & 21.7 \\
\hline Division 5 & 14.4 & 8.5 & 23.7 \\
\hline Division 6 & 14.9 & 16 & 13.1 \\
\hline Division 7 & 13.4 & 19.5 & 3.6 \\
\hline Division 8 or lower & 11.4 & 17.7 & 1.3 \\
\hline Non-league & 8 & 10.9 & 3.5 \\
\hline \multirow[t]{2}{*}{ Recreational } & 15.5 & 17.2 & 12.8 \\
\hline & Mean (SD) & Mean (SD) & Mean (SD) \\
\hline Years played & $15.8(7.2)$ & $17.2(7.6)$ & $13.6(5.9)$ \\
\hline
\end{tabular}

playing. More ACL injuries were sustained while playing on artificial grass than on natural grass. The risk of ACL injury was highest early in the football game with $47.2 \%$ sustaining the injury in the first $30 \mathrm{~min}$ and $23.9 \%$ already in the first 15 min (Table 3).

The Swedish football season is usually played from April until the beginning of November with a brake in July and the ACL injuries are more frequent in season compared to the off season with a slight peak in May (Fig. 1). Most of the ACL injuries were sustained during the weekend (Fig. 2).

Players changing to a higher level of play had a higher rate of ACL injuries than players changing to a lower level. This difference was especially seen in female football players with $19.7 \%$ of ACL injuries being sustained by players going to a higher division compared to $7 \%$ for those going to a lower division. One out of 4 of the males and 1 out of 3 of the females had a coach change before or during the season of the injury and the frequencies of ACL injuries were higher if the team changed coach during the season. In the 3 months prior to the ACL injury roughly twice as many players claim to have lost weight compared having gained weight. Knee control exercises to warm up was used by $31.4 \%$ of the female players and $15.6 \%$ of the male players. One in five reported to have had an injury or symptoms in the 6 weeks leading up to the ACL injury. A previous ACL injury was reported by $17.9 \%$ of the females and by $14 \%$ of the males. Further data and other influencing factors are found in Table 4.

The median in days until ACL diagnosis was 21, but the mean was 93 days, and this large difference was due to a few extreme outliers where the diagnosis was not made until several years after the suspected initial injury. Magnetic resonance imaging (MRI) was performed on $73.3 \%$ of the players and $54.6 \%$ had plain radiography. Associated injuries were reported by $46.7 \%$ of the players. In total, $60 \%$ of the players plan on returning to football after the ACL injury and a subanalysis found that younger players $(p<0.001)$ and players in the higher divisions $(p<0.001)$ are more likely to plan on returning to football. Surgical treatment was planned for $94.9 \%$ of the players (Table 5).

\section{Discussion}

The present study found that a high number of players reported a coach change before or during the season when they sustained their ACL injury, one in four for the males and one in three for the females. In male professional 
Table 3 Injury occurrence data for ACL-injured football players $(n=2875)$

\begin{tabular}{|c|c|c|c|}
\hline Variable & $\begin{array}{l}\text { Total } \\
\%\end{array}$ & $\begin{array}{l}\text { Male } \\
\%\end{array}$ & $\begin{array}{l}\text { Female } \\
\%\end{array}$ \\
\hline \multicolumn{4}{|l|}{ Injured leg } \\
\hline Right & 53.5 & 54.3 & 52.2 \\
\hline Left & 46.5 & 45.7 & 47.8 \\
\hline \multicolumn{4}{|c|}{ Activity at time of injury } \\
\hline Home game & 33.9 & 34.2 & 33.5 \\
\hline Away game & 31.8 & 27.9 & 38 \\
\hline Practice & 24.8 & 27.1 & 21.2 \\
\hline Other & 9.5 & 10.8 & 7.3 \\
\hline \multicolumn{4}{|l|}{ Injury mechanism } \\
\hline Contact & 40.9 & 39.9 & 42.5 \\
\hline Non-contact & 59.1 & 60.1 & 57.5 \\
\hline \multicolumn{4}{|l|}{ Referees decision } \\
\hline Red card & 0.5 & 0.4 & 0.6 \\
\hline Yellow card & 3.4 & 4 & 2.5 \\
\hline Freekick & 12.2 & 12.5 & 11.8 \\
\hline Other & 20.8 & 20.3 & 21.5 \\
\hline No action & 63.1 & 62.8 & 63.6 \\
\hline \multicolumn{4}{|l|}{ Started the game } \\
\hline Yes & 86.1 & 85.7 & 86.6 \\
\hline Substituted on & 13.9 & 14.3 & 13.3 \\
\hline \multicolumn{4}{|l|}{ Action after injury } \\
\hline Continued playing & 3.9 & 4.3 & 3.1 \\
\hline Stopped playing & 86.6 & 85.3 & 88.8 \\
\hline Unsure & 9.5 & 10.4 & 8.1 \\
\hline \multicolumn{4}{|l|}{ Pitch surface } \\
\hline Grass & 37.7 & 37.3 & 38.4 \\
\hline Artificial grass & 45.7 & 44.8 & 47.2 \\
\hline Gravel & 1.4 & 1.6 & 1 \\
\hline Indoor & 12.1 & 12.8 & 11.1 \\
\hline Other & 3.1 & 3.5 & 2.4 \\
\hline \multicolumn{4}{|l|}{ Game minute } \\
\hline Mean (SD) & $40.3(26.4)$ & $39.7(26.1)$ & $41.3(26.9)$ \\
\hline $0-15$ & 23.9 & 24 & 23.9 \\
\hline $16-30$ & 23.3 & 23.9 & 22.1 \\
\hline $31-45$ & 13.3 & 14.3 & 11.9 \\
\hline $46-60$ & 13.9 & 13.7 & 14.1 \\
\hline $61-75$ & 14.8 & 13.8 & 16.4 \\
\hline $76-90+$ & 10.8 & 10.3 & 11.6 \\
\hline
\end{tabular}

players, previous studies have found that the leadership style of the coach influences the injury burden of the team and that a high turnover of coaches leads to an increase of muscle injuries [7,9]. The female players reported that $20.8 \%$ of the ACL injuries were sustained when the team changed coach during the season. Studies on the influence of a coach change on the risk of ACL injuries in amateur football are lacking but highly warranted given the results in the present study. Another notable founding that warrant a closer examination was the high number of ACL injuries in female players going to a higher division. An increased risk of ACL injury following a change to a higher division was previously only detected in a smaller group of elite male players [17].

For most of the variables examined in the present study, there were only small differences between male and female players in this large sample on football-specific epidemiological data on ACL injuries. Besides the expected gender differences in average height and weight, the females in the study were almost 5 years younger. This age difference is at least partly explained by female players retiring from football at a younger age than male players [22]. More male players reported that they were left-footed dominant and this is consistent with a meta-analysis on left-handedness and gender [18]. ACL injuries were more common in the early part of the game and nearly 1 in 4 occurred in the first $15 \mathrm{~min}$. This is in line with previous studies and indicates that the ACL injury in football players is not primarily due to fatigue [6]. Preventive programs have proven to be effective in reducing the risk of non-contact ACL injuries in football $[13,15,25,26]$. Given the increased risk during the early part of football games, implementing knee-specific exercises in the pre-game warm up could possibly help to further reduce the number of ACL injuries. The present study found that $31.4 \%$ of the females and only $15.6 \%$ of the male players reported that they use a knee-specific warm up program. This clearly indicate that even with the strong evidence of the effectiveness of the preventive programs, implementation and compliance remain a challenge. Continued efforts to promote neuro-muscular preventive programs are vital in reducing the number of ACL injuries in football. Although the frequencies differ between studies most have found that ACL injuries are more common in non-contact than contact situations $[3,5,10,24]$. It is not easy to exactly define what a contact situation is in football, but in the present study, 6 out of 10 of the ACL injuries occurred in non-contact situations as defined by the players themselves. Previous studies have found that the incidents of ACL injuries are considerably higher during games compared to in training $[5,12,24$, 28]. In the present study, $66 \%$ of all ACL injuries happened during games. If the referee's decision is used to assess the severity of the contact situation during games, only $0.5 \%$ resulted in a red card and 3.4\% in a yellow card. Foul play should of course always be discouraged to protect the football players, but it does not appear like stricter rules would reduce the number of ACL injuries in football in a significant way. More ACL injuries occurred on artificial grass than on natural grass. Since the exposure to the different pitch surfaces was unknown, it could not be concluded if this difference was significant or not. However, given the advantages of artificial grass in densely populated areas or in cold climate regions, it would be unfeasible to convert artificial 


\section{ACL injuries per month (\%)}

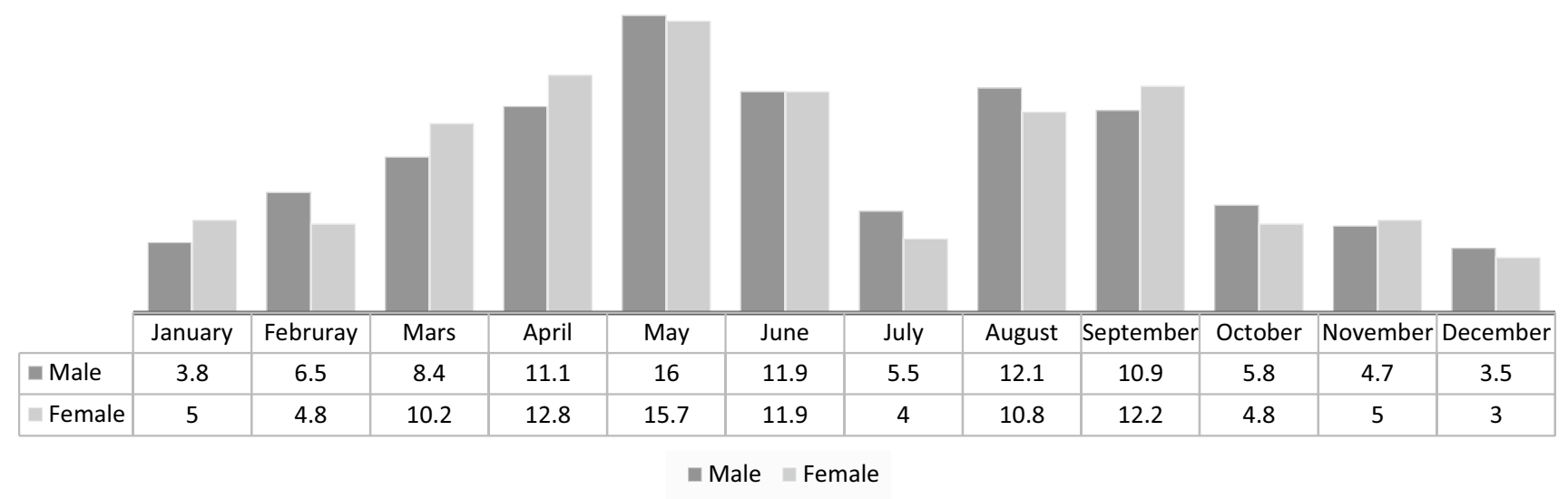

Fig. 1 Frequencies of ACL injuries in football per month in Sweden ( $n$ 2619)

Fig. 2 Frequencies of ACL injuries in football per weekday in Sweden $(n$ 2312)

\section{$A C L$ injures per weekday (\%)}

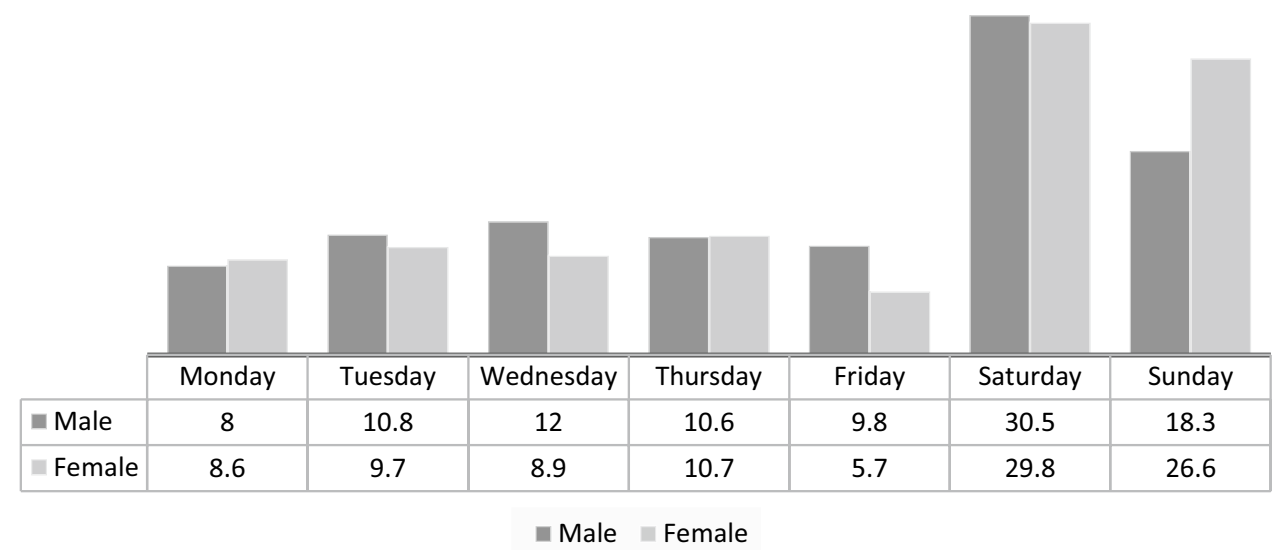

grass pitches to natural grass in an attempt to slightly reduce the risk of ACL injuries. Previous follow-ups on ACL reconstructed football players from the SNKLR found a return to football rate of 51-54\%, and in this study, $60 \%$ of the players stated that they planned on returning to football [21, 23]. Consequently, the remaining $40 \%$ indicated that they did not intent to return to football. Although that number is in line with the previous studies on return to football in Sweden, the fact that they have made that decision before or shortly after the surgery when the questionnaire was filled out by many of the players is to our knowledge novel information and requires further investigation.

One obvious limitation in the present study and studies of this kind is of course the lack of exposure data or a matched control group. That limits the possibility for inference on the results obtained. Given the heterogenic and large group of football players and the number of variables included, the study is valuable in providing a foundation from which to develop hypothesis and ideas on how to reduce ACL injuries in football.

The present study highlights the need to further introduce and adhere to neuro-muscular training programs, and a special attention should be directed to teams changing the coach and players going to a higher division. 
Table 4 Preparation and influencing factors for ACL injuries in football players $(n=2875)$

\begin{tabular}{|c|c|c|c|}
\hline Variable & $\begin{array}{l}\text { Total } \\
\%\end{array}$ & $\begin{array}{l}\text { Male } \\
\%\end{array}$ & $\begin{array}{l}\text { Female } \\
\%\end{array}$ \\
\hline \multicolumn{4}{|l|}{ Club change for this season } \\
\hline Yes & 11.8 & 11.5 & 12.2 \\
\hline No & 88.2 & 88.5 & 87.8 \\
\hline \multicolumn{4}{|l|}{ Division change this season } \\
\hline No & 77 & 79.3 & 73.3 \\
\hline Yes, to a higher & 14.6 & 11.5 & 19.7 \\
\hline Yes, to a lower & 8.4 & 9.2 & 7 \\
\hline \multicolumn{4}{|l|}{ Coach change } \\
\hline No & 72.3 & 75.5 & 67.3 \\
\hline During the season & 17.3 & 15.2 & 20.8 \\
\hline Before the season & 10.4 & 9.4 & 11.9 \\
\hline \multicolumn{4}{|l|}{ Weight change previous 3 months } \\
\hline About the same & 78.9 & 77 & 81.9 \\
\hline Gained weight & 7.2 & 7.6 & 6.6 \\
\hline Lost weight & 13.9 & 15.4 & 11.4 \\
\hline \multicolumn{4}{|l|}{ New football shoes last month } \\
\hline Yes & 11.8 & 13 & 10 \\
\hline No & 88.2 & 87 & 90 \\
\hline \multicolumn{4}{|l|}{ Shoe type at time of injury } \\
\hline Firm ground-permanent studs & 62.4 & 63.5 & 60.6 \\
\hline Soft ground-screw-in studs & 1.8 & 2.6 & 0.5 \\
\hline Artificial grass & 19.7 & 16.8 & 24.4 \\
\hline Indoor & 6.3 & 7.2 & 4.9 \\
\hline Other & 9.8 & 10 & 9.5 \\
\hline \multicolumn{4}{|l|}{ Weather conditions } \\
\hline Sun & 42.5 & 41.5 & 44 \\
\hline Cloudy & 29.3 & 29.7 & 28.5 \\
\hline Rain & 6.8 & 6.9 & 6.7 \\
\hline Snow & 3.7 & 3.9 & 3.4 \\
\hline Other & 17.7 & 17.9 & 17.3 \\
\hline \multicolumn{4}{|l|}{ Games played in the previous 7 days } \\
\hline 0 & 37.3 & 35.2 & 40.9 \\
\hline 1 & 50.4 & 49.4 & 52 \\
\hline 2 or more & 12.3 & 15.3 & 7.1 \\
\hline \multicolumn{4}{|c|}{ Warm up using knee control exercises } \\
\hline Yes & 21.7 & 15.6 & 31.4 \\
\hline No & 78.3 & 84.4 & 68.6 \\
\hline \multicolumn{4}{|l|}{ Previous injury } \\
\hline ACL & 15.5 & 14 & 17.9 \\
\hline PCL & 1.2 & 1.2 & 1.2 \\
\hline \multicolumn{4}{|c|}{ Symptoms or injury in the last 6 weeks before the ACL injury } \\
\hline Yes & 19.8 & 18.7 & 21.6 \\
\hline No & 80.2 & 81.3 & 78.4 \\
\hline \multicolumn{4}{|c|}{ Distribution of symptoms and injuries per body part } \\
\hline Head & 4.2 & 2.7 & 6.2 \\
\hline Neck & 2.5 & 1.5 & 3.8 \\
\hline Back & 18.9 & 19.4 & 18.3 \\
\hline Groin & 14 & 16.1 & 11.3 \\
\hline Hip & 9.3 & 7.9 & 11.3 \\
\hline Thigh & 16 & 13.6 & 19.2 \\
\hline
\end{tabular}


Table 4 (continued)

\begin{tabular}{llll}
\hline Variable & $\begin{array}{l}\text { Total } \\
\%\end{array}$ & $\begin{array}{l}\text { Male } \\
\%\end{array}$ & $\begin{array}{l}\text { Female } \\
\%\end{array}$ \\
\hline Knee & 60 & 62.7 & 56.3 \\
Ankle/foot & 25.4 & 23.6 & 27.9 \\
\hline
\end{tabular}

Table 5 Time until ACL diagnosis, imaging, associated injuries, intention to return, and treatment data for ACL-injured football players $(n=2875)$

\begin{tabular}{|c|c|c|c|}
\hline Variable & Total & Male & Female \\
\hline \multicolumn{4}{|c|}{ Days until ACL diagnosis } \\
\hline Median & 21 & 24 & 21 \\
\hline \multirow[t]{2}{*}{ Mean (SD) } & $93(260)$ & $106(285)$ & $73(214)$ \\
\hline & $\%$ & $\%$ & $\%$ \\
\hline \multicolumn{4}{|l|}{ Imaging } \\
\hline MRI & 73.3 & 70.9 & 77 \\
\hline X-ray & 54.6 & 55.3 & 53.5 \\
\hline $\mathrm{CT}$ & 2.8 & 2.6 & 3.1 \\
\hline Ultrasonography & 6.5 & 7.2 & 5.4 \\
\hline \multicolumn{4}{|l|}{ Associated injuries } \\
\hline Any type & 46.7 & 47.4 & 45.6 \\
\hline Cartilage & 13 & 14.2 & 11.2 \\
\hline Medial meniscus & 32.2 & 33.9 & 29.6 \\
\hline Lateral meniscus & 27.7 & 29.9 & 24.1 \\
\hline LCL & 10 & 9.9 & 10.1 \\
\hline MCL & 13.7 & 13.2 & 14.6 \\
\hline PCL & 4.3 & 4.1 & 4.6 \\
\hline \multicolumn{4}{|c|}{ Plan on returning to football } \\
\hline Yes & 60 & 58.3 & 62.6 \\
\hline No & 40 & 41.7 & 37.4 \\
\hline \multicolumn{4}{|l|}{ Treatment planed } \\
\hline Surgical & 94.9 & 93.9 & 96.6 \\
\hline Non-surgical & 5.1 & 6.1 & 3.4 \\
\hline
\end{tabular}

\section{Conclusions}

Neuromuscular training programs have proven to reduce ACL injuries but greater adherence to these remain a challenge as only 1 in 5 of the ACL-injured football players report using them. Teams changing coach and players going to a higher division appear to have an increased risk of ACL injury warranting attention and further investigations.

Funding Open access funding provided by Karolinska Institute. There has been no other funding of the present research.

\section{Declarations}

Conflict of interest The author(s) declare that theyhave no competing interests.
Ethical approval The research was approved by the regional ethics committee in Stockholm ID 2011/337-31/3 and Linköping ID 202003747.

Open Access This article is licensed under a Creative Commons Attribution 4.0 International License, which permits use, sharing, adaptation, distribution and reproduction in any medium or format, as long as you give appropriate credit to the original author(s) and the source, provide a link to the Creative Commons licence, and indicate if changes were made. The images or other third party material in this article are included in the article's Creative Commons licence, unless indicated otherwise in a credit line to the material. If material is not included in the article's Creative Commons licence and your intended use is not permitted by statutory regulation or exceeds the permitted use, you will need to obtain permission directly from the copyright holder. To view a copy of this licence, visit http://creativecommons.org/licenses/by/4.0/. 


\section{References}

1. Ahlden M, Samuelsson K, Sernert N, Forssblad M, Karlsson J, Kartus J (2012) The Swedish National Anterior Cruciate Ligament Register: a report on baseline variables and outcomes of surgery for almost 18,000 patients. Am J Sports Med 40:2230-2235

2. Ajuied A, Wong F, Smith C, Norris M, Earnshaw P, Back D et al (2014) Anterior cruciate ligament injury and radiologic progression of knee osteoarthritis: a systematic review and meta-analysis. Am J Sports Med 42:2242-2252

3. Alentorn-Geli E, Myer GD, Silvers HJ, Samitier G, Romero D, Lazaro-Haro C et al (2009) Prevention of non-contact anterior cruciate ligament injuries in soccer players. Part 1: mechanisms of injury and underlying risk factors. Knee Surg Sports Traumatol Arthrosc 17:705-729

4. Ardern CL, Taylor NF, Feller JA, Webster KE (2014) Fifty-five per cent return to competitive sport following anterior cruciate ligament reconstruction surgery: an updated systematic review and meta-analysis including aspects of physical functioning and contextual factors. Br J Sports Med 48:1543-1552

5. Bjordal JM, Arnly F, Hannestad B, Strand T (1997) Epidemiology of anterior cruciate ligament injuries in soccer. Am J Sports Med 25:341-345

6. Della Villa F, Buckthorpe M, Grassi A, Nabiuzzi A, Tosarelli F, Zaffagnini S et al (2020) Systematic video analysis of ACL injuries in professional male football (soccer): injury mechanisms, situational patterns and biomechanics study on 134 consecutive cases. Br J Sports Med 54:1423-1432

7. Dönmez G, Kudaş S, Yörübulut M, Yıldırım M, Babayeva N, Torgutalp Ş (2020) Evaluation of muscle injuries in professional football players: does coach replacement affect the injury rate? Clin J Sport Med 30:478-483

8. Ekstrand J, Krutsch W, Spreco A, van Zoest W, Roberts C, Meyer $T$ et al (2020) Time before return to play for the most common injuries in professional football: a 16-year follow-up of the UEFA Elite Club Injury Study. Br J Sports Med 54:421-426

9. Ekstrand J, Lundqvist D, Lagerback L, Vouillamoz M, Papadimitiou N, Karlsson J (2018) Is there a correlation between coaches' leadership styles and injuries in elite football teams? A study of 36 elite teams in 17 countries. Br J Sports Med 52:527-531

10. Fauno P, Wulff Jakobsen B (2006) Mechanism of anterior cruciate ligament injuries in soccer. Int J Sports Med 27:75-79

11. Gifstad T, Foss OA, Engebretsen L, Lind M, Forssblad M, Albrektsen $\mathrm{G}$ et al (2014) Lower risk of revision with patellar tendon autografts compared with hamstring autografts: a registry study based on 45,998 primary ACL reconstructions in Scandinavia. Am J Sports Med 42:2319-2328

12. Grassi A, Macchiarola L, Filippini M, Lucidi GA, Della Villa F, Zaffagnini S (2020) Epidemiology of anterior cruciate ligament injury in Italian First Division soccer players. Sports Health 12:279-288

13. Huang YL, Jung J, Mulligan CMS, Oh J, Norcross MF (2019) A majority of anterior cruciate ligament injuries can be prevented by injury prevention programs: a systematic review of randomized controlled trials and cluster-randomized controlled trials with meta-analysis. Am J Sports Med 48:1505-1515 (363546519870175)

14. Krutsch W, Gündisch C, Nerlich M, Angele P (2017) Prevention of ACL injuries in Olympic sports-first step for a national "ACL registry in football.” Br J Sports Med 51:346-346
15. Krutsch W, Lehmann J, Jansen P, Angele P, Fellner B, Achenbach $\mathrm{L}$ et al (2020) Prevention of severe knee injuries in men's elite football by implementing specific training modules. Knee Surg Sports Traumatol Arthrosc 28:519-527

16. Krutsch W, Memmel C, Krutsch V, Angele P, Tröß T, Der A, FÜnten $\mathrm{K}$ et al (2020) High return to competition rate following ACL injury - a 10-year media-based epidemiological injury study in men's professional football. Eur J Sport Sci 20:682-690

17. Krutsch W, Zeman F, Zellner J, Pfeifer C, Nerlich M, Angele P (2016) Increase in ACL and PCL injuries after implementation of a new professional football league. Knee Surg Sports Traumatol Arthrosc 24:2271-2279

18. Papadatou-Pastou M, Martin M, Munafò MR, Jones GV (2008) Sex differences in left-handedness: a meta-analysis of 144 studies. Psychol Bull 134:677-699

19. Rabin R, de Charro F (2001) EQ-5D: a measure of health status from the EuroQol Group. Ann Med 33:337-343

20. Roos EM, Roos HP, Lohmander LS, Ekdahl C, Beynnon BD (1998) Knee Injury and Osteoarthritis Outcome Score (KOOS) development of a self-administered outcome measure. J Orthop Sports Phys Ther 28:88-96

21. Sandon A, Engstrom B, Forssblad M (2020) High risk of further anterior cruciate ligament injury in a 10-year follow-up study of anterior cruciate ligament-reconstructed soccer players in the Swedish National Knee Ligament Registry. Arthroscopy 36:189-195

22. Sandon A, Söderström T, Stenling A, Forssblad M (2021) Can talented youth soccer players who have undergone anterior cruciate ligament reconstruction reach the elite level? Am J Sports Med 49:384-390

23. Sandon A, Werner S, Forssblad M (2015) Factors associated with returning to football after anterior cruciate ligament reconstruction. Knee Surg Sports Traumatol Arthrosc 23:2514-2521

24. Schiffner E, Latz D, Grassmann JP, Schek A, Thelen S, Windolf $\mathrm{J}$ et al (2018) Anterior cruciate ligament ruptures in German elite soccer players: Epidemiology, mechanisms, and return to play. Knee 25:219-225

25. Silvers-Granelli HJ, Bizzini M, Arundale A, Mandelbaum BR, Snyder-Mackler L (2017) Does the FIFA 11+ injury prevention program reduce the incidence of ACL injury in male soccer players? Clin Orthop Relat Res 475:2447-2455

26. Walden M, Atroshi I, Magnusson H, Wagner P, Hagglund M (2012) Prevention of acute knee injuries in adolescent female football players: cluster randomised controlled trial. BMJ 344:e3042

27. Walden M, Hagglund M, Magnusson H, Ekstrand J (2016) ACL injuries in men's professional football: a 15-year prospective study on time trends and return-to-play rates reveals only $65 \%$ of players still play at the top level 3 years after ACL rupture. Br J Sports Med 50:744-750

28. Walden M, Hagglund M, Magnusson H, Ekstrand J (2011) Anterior cruciate ligament injury in elite football: a prospective threecohort study. Knee Surg Sports Traumatol Arthrosc 19:11-19

Publisher's Note Springer Nature remains neutral with regard to jurisdictional claims in published maps and institutional affiliations. 